\title{
Effective Harness of Wind Energy Turbines
}

\author{
Ahmed Abdolkhalig ${ }^{1 *}$, Qing Fang ${ }^{2}$ and Ashraf Mohamed ${ }^{1}$ \\ ${ }^{1}$ School of Electrical and Electronic Engineering, University of Tobruk, Libya \\ ${ }^{2}$ School of Electrical and Electronic Engineering, University of Adelaide, Australia
}

\begin{abstract}
There are many types of renewable energy resources such as wind, solar, water and more. Electrical Energy produced by wind resource is considered the most common of renewable energy productions in many countries. As of 2015 , at least 83 countries around the world are using energy that comes from wind to supply their electric grids. In 2014 , global wind energy capacity expanded $16 \%$. Yearly, wind energy production is growing rapidly and has reached around $4 \%$ of worldwide electric energy usage, $11.4 \%$ in the EU. This paper investigates the effective harnessing of electrical energy from wind energy resources and discusses various opportunities and challenges including cost effectiveness. It also investigates the impact of wind energy to industrial area and human being.
\end{abstract}

Keywords: Wind turbine generator; Cost effect; Micro-grid; Inverters

\section{Introduction}

Since many centuries ago, people have been harnessed wind energy to pump water, grind grain and more. Wind machines have been used in Persia as early as $200 \mathrm{BC}$ for grinding the grain and the earliest practical windmills have been built in Sistan, Iran in the $7^{\text {th }}$ century [1]. Windmills have been used also in 14th century Holland for pumping the water. The earliest known electricity-generating windmill was dedicated for charging batteries in 1887 by James Blyth in Scotland [2]. It is also known that the first use of a large windmill for generating electricity was in Cleveland, Ohio, in 1888 by Charles Brush $[3,4]$.

The developments of large-scale wind turbines continued from the first quarter of the 20th century in European countries, mostly Germany, Denmark and France [5]. At the end of the year 1983, there were approximately 4600 wind turbines operating out of California [6]. There turbines together produced about $300 \mathrm{MW}$ of electricity. The price changes of wind power electricity went down from 14 cents per $\mathrm{kWh}$ in 1985 to 5 cents per kWh in 1994 which made the wind power a greater competitor in the electricity market. Today, environmental issues like increased pollution and greenhouse effects have put industrial, transport, electrical power, fuel consumption and more into a big problem which is how to reduce the pollution, environmental issues and greenhouse effects.

As wind energy resources do not generate emissions or hazardous waste, do not require significant amounts of water to operate, and do not require the extraction of natural resources, they are considered the less harmful to environment than any other conventional and alternative electrical energy sources [7]. Also, total fuel cycle of wind energy resource (including manufacturing of the steel and concrete for the turbines and towers) emits very few pollutants [8]. Due to these decreased emissions, wind energy's non-economic costs (the quantification of impact on human mortality and morbidity, man-made structures, global warming, crops, amenity losses, and ecosystems) are among the lowest when compared with other energy generation $[8,9]$.

In addition, wind energy resources have fewer impacts on the land than many other energy resources. Even though utility-scale wind projects generally require 15-50 acres per MW of installed capacity, they only occupy about $5 \%$ or less of that area, leaving the remainder available for compatible uses such as farming or ranching. Importantly, if a wind farm is dismantled, the land can easily be restored to its natural state [9].
Moreover, wind energy resource has also become cost-competitive with conventional and other renewable energy sources, and is clearly cheaper than solar and nuclear energy [10]. If environmental costs are included in the cost calculation, wind energy is even more economical, because it does no costly damage to the environment or public health [9].

Therefore, the objective of this paper is to look into the existing operational conditions of wind energy and to find obstacles that preventing the effective harass of wind energy.

The paper is organized as follows: In Section 2, an overview of wind energy turbine is given. Advantages and disadvantages of two basic types of wind turbine are discussed and power formulas of them are presented. Difficulties of direct connect of energy produced to grid and how inverter should be selected to tackle this problem is explained in Section 3. In Section 4, an example is given on how wind energy can be effective harnessed to made the cost fallen. Section 5, explains how microgrids can be great choice for isolated community. Section 6 suggests hybrid wind-PV-energy storage system to complement each other and give option of selecting the rate of wind generator and PV. In section 7 , conclusions are summarized.

\section{Overview of Wind Energy Resources}

To convert from wind energy to electrical energy, there are a few components included, a turbine, a gear box (Drive train), a generator and a converter, and the assembling of all these components is called wind turbine generator (WTG) (Figure 1). From an industrial point of view, the major types of electric generators adopted or under serious consideration for wind power are using a Doubly Fed Induction Generator (DFIG).

Basically, there are two types of WTG [11], horizontal axis and vertical axis WTG. Those two types are shown in Figure 2. The

*Corresponding author: Ahmed Abdolkhalig, School of Electrical and Electronic Engineering, University of Tobruk, Libya, Tel: +218911002568; E-mail: almsraty@hotmail.com

Received April 30, 2018; Accepted May 18, 2018; Published May 23, 2018

Citation: Abdolkhalig A, Fang Q, Mohamed A (2018) Effective Harness of Wind Energy Turbines. J Electr Electron Syst 7: 256. doi: 10.4172/2332-0796.1000256

Copyright: $\odot 2018$ Abdolkhalig A, et al. This is an open-access article distributed under the terms of the Creative Commons Attribution License, which permits unrestricted use, distribution, and reproduction in any medium, provided the original author and source are credited. 


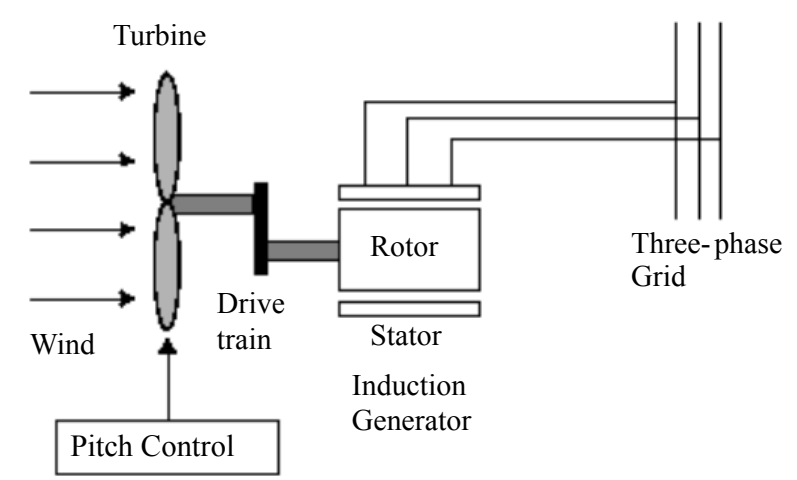

Source: Mathworks.com

Figure 1: Example of WTG (Induction Generator).

advantages and disadvantages of each of them can be summarized as follows.

\section{Horizontal axis WTG (Upwind and downwind horizontal axis WTGs)}

The advantage of a downwind WTG is it allows the wind itself to control the yaw, so it orients itself correctly to wind direction. There is a problem with this kind of WTG that is the tower is affected by the wind shadowing.

Upwind WTGs need a complex yaw control system to keep their blades facing into the wind. However, regardless of that complexity added, upwind WTGs operate more smoothly and deliver more efficient power [12]. The advantages of horizontal axis WTG make it the most common uses from the various WTGs.

\section{Vertical axis WTG (Darrieus WTG)}

Vertical axis machine has main advantages which are: first, it doesn't need any kind of yaw control to keep them facing into the wind (Figure 2). Secondly, the heavy machinery contained in the nacelle can be located down on the ground, where it can be maintained and serviced easily [13-15]. Also, there are many disadvantages of the vertical axis WTGs. The major disadvantage is the blades are relatively close to the ground where wind speeds are lower. Darrieus rotors have very little starting torque at low-speed winds. In higher higher-speed winds, the output power must be controlled to protect the generator [15]. As a result, the output power is much lower than the horizontal WTGs.

There are a few basic formulas which are very important for the wind energy applications. Those formulas can be summarized as follows:

Kinetic energy:

$K . E .=\frac{1}{2} m v^{2}$

Power through area $A$ :

$$
\begin{aligned}
& A=\frac{\text { Energy }}{\text { Time }}=\frac{1}{2}\left(\frac{\text { Mass }}{\text { Time }}\right) v^{2} \\
& \left(\frac{\text { Mass passing through } A}{\text { Time }}\right)=m=\rho A v
\end{aligned}
$$

If those equations are combined, the output power of the WTG can be given by the following equation

$$
P_{m}=c_{p}(\lambda, \beta) \frac{\rho A}{2} v_{\text {wind }}^{3},
$$

where:

- $P_{m}$ Mechanical output power of the WTG (W)

- $C_{P}$ Performance coefficient of the WTG

- $\rho$ Air density (At $15 \mathrm{C}^{\circ}, \rho=1.225 \mathrm{~kg} / \mathrm{m}^{3}$ )

- ${ }^{A}$ WTG swept area $\left(\mathrm{m}^{2}\right)$

- $\quad v_{\text {wind }}$ Wind speed $(\mathrm{m} / \mathrm{s})$

- $\lambda$ Tip speed ratio of the rotor blade tip speed to wind speed

- $\quad \beta$ Blade pitch angle (deg)

In the Equation (4) above, it can be noted that the wind power increases as the cube of wind-speed. The mechanical power $P_{m}$ as a function of generator speed, for different wind speeds and for blade pitch angle $\beta=0$ degree, is illustrated Figure 3 below. This figure is
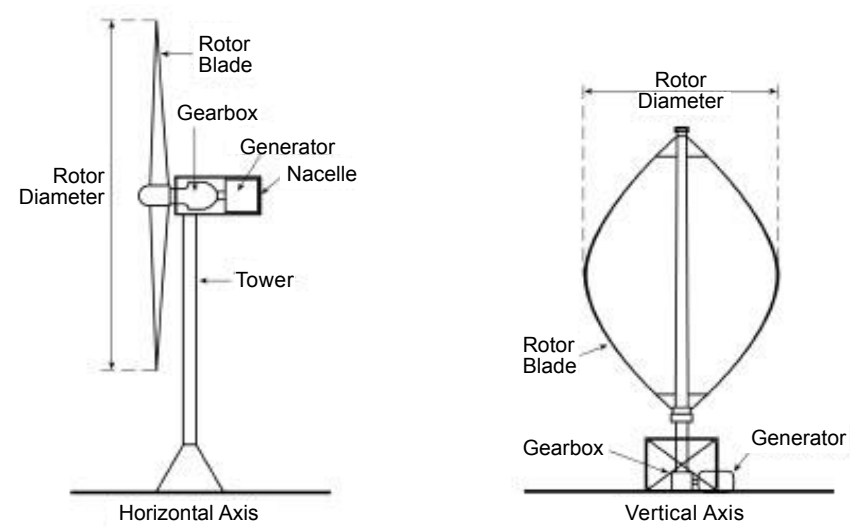

Figure 2: Diagram of two basic types WTGs.

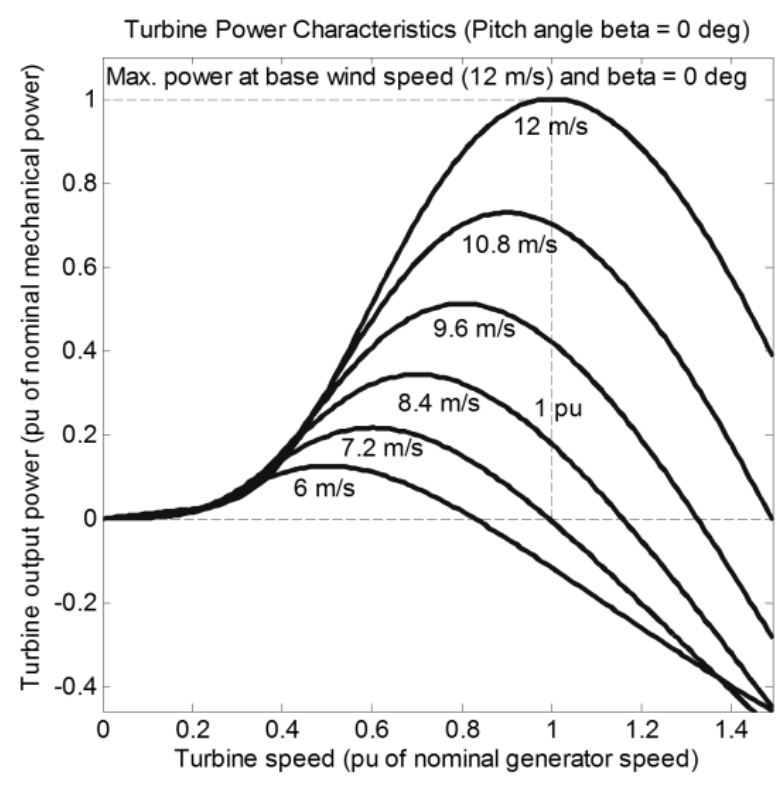

Figure 3: $P_{m}$ as a function of generator speed. 
obtained with the default parameters (base wind speed $=12 \mathrm{~m} / \mathrm{s}$, maximum power at base wind speed $=0.73 \mathrm{pu}(\mathrm{kp}=0.73)$ and base rotational speed $=1.2 \mathrm{pu}$ )

The swept area is a bit complicated to be figured out. For simplification, this area can be approximated to the area that it is about two-thirds the area of a rectangle and with width equal to the maximum rotor width and with height equal to the vertical extent of the blades [4].

Generally, there are three most important variables that determine how much electricity of a WTG can produce [16]. Those variables are: wind speeds, blade radius; and air density. Wind speeds usually not constant and the stronger winds will produce more energy, but the efficiency of the WTG (as $C_{p}$ in eqn. (4)) can be reached to a certain maximum point then drops.

Some types of WTGs usually don't operate when the wind speed is below 8 miles per hour (e.g., vertical type with three blades). The peak power can be generated by the WTG when wind speed is between 25 and 55 miles per hour. Most WTGs will be shut down at about 55 miles per hour because this high wind speed can damage them. The vertical disk created by the rotating blades can be considered as one of the factors that determine how much electricity that the WTG can produce.

Larger area of wind blades "harvest" means a greater yield will be. In some cases, four times power can be produced if the blade, or rotor, diameter can be doubled. In practical, WTGs come in a variety of sizes and usually the larger ones are usually more efficient. If the WTG is tall, it can reach to the greater winds found at higher altitude and are less subject to turbulence.

It is well known that, in the first few hundred meters above the ground, wind speeds is more affected by the friction that when it moves across the earth's surface. Smoother surface such as a calm sea, will has a very little resistance, and the speed variation with elevation is only modest. High irregularities such as forest and buildings can slow surface winds. The impact of the roughness of the earth's surface on wind-speeds can be characterized is shown the eqn. (5) below.

$$
\left(\frac{v}{v_{o}}\right)=\left(\frac{H}{H_{o}}\right) \wedge \alpha
$$

The amount of kinetic energy that wind applies to a rotor can be affected by the air density. The air density can be considered as a function of altitude. The higher altitude locations have lower air pressure and lighter air, so they are less productive WTG locations. The dense, "heavy" air near sea level drives rotors relatively more effectively. The eqn. (6) below is expressing the air density:

$$
\rho=\frac{P \times M \cdot W \cdot \times 10^{-3}}{R T}
$$

where:

- $\quad P$ is the absolute pressure (atm)

- $R$ is the idea gas constant $=0.082057 \mathrm{~L}_{\text {atm }} \mathrm{mol}^{-1} \mathrm{~K}^{-1}$

- $\quad T$ is the absolute temperature $(\mathrm{K})$

- $\quad$ M.W. stands for the molecular weight of the gas (g/mol).

\section{Variable Speed Wind Turbine Generator}

The electrical energy produced from any wind energy resource cannot be connected directly to the grid, because it is voltages and frequencies are varying with wind speed [17]. To tackle this problem, a variable speed WTG is used. In variable speed machines the generator is connected to the grid by an electronic inverter system $[18,19]$.

For synchronous generators and for induction generators without slip rings, this inverter system is connected between the stator of the generator and the grid where the total power production must be fed through the inverter.

For induction generators with slip rings the stator of the generator is connected to the grid directly. Only the rotor of the generator is connected to the grid by an electronic inverter (Figure 4). This gives the advantage that only a part of the power production is fed through the inverter. That means the nominal power of the inverter system can be less than the nominal power of the WTG.

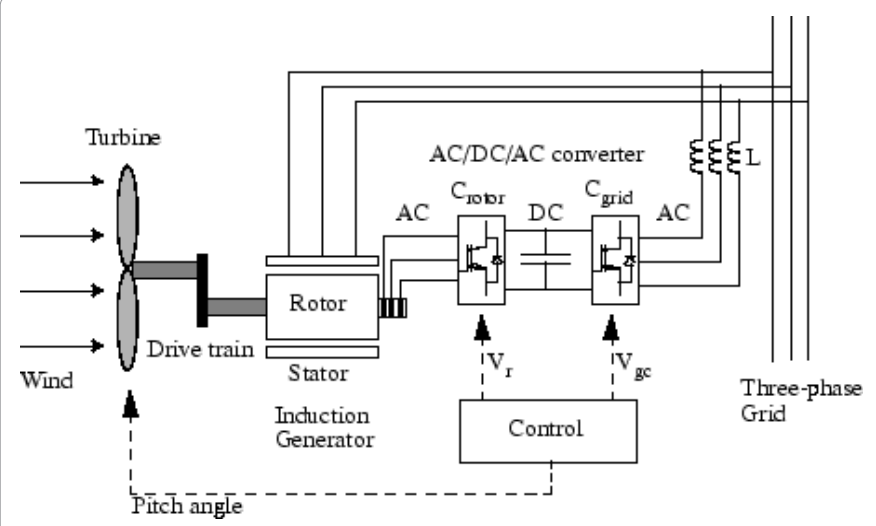

Source: Mathworks.com

Figure 4: Variable speed WTG with double fed induction generator.

In general the nominal power of the inverter is the half of the power of the WTG, enabling a rotor speed variation in the range of half the nominal speed. By the control of active power of the inverter, it is possible to vary the rotational speed of the generator and thus of the rotor of the WTG. If the WTG operates at variable rotational speed, the electric frequency of the generator varies and must therefore be decoupled from the frequency of the grid. This can be achieved by an inverter system.

There are two different types of inverter systems: grid commutated and self-commutated inverter systems. The grid commutated inverters are mainly thyristor inverters (e.g., 6 or 12 pulse). This type of inverter produces integer harmonics like the 5 th, 7 th, 11th, 13th order (frequencies of $250,350,550,650 \mathrm{~Hz}$, etc.), which in general must be reduced by harmonic filters. On the other hand thyristor inverter is not able to control the reactive power. Their behaviour concerning reactive power is similar to the behaviour of an induction generator they consume inductive reactive power.

Self-commutated inverter systems are mainly pulse width modulated (PWM) inverter, where IGBTs (Insulated Gate Bipolar Transistor) are used. This type of inverter gives the advantage that in addition to the control of the active power the reactive power is also controllable. That means the reactive power demand of the generator can be delivered by the PWM-inverter. One disadvantage is the production of inter-harmonics.

In general these inter-harmonics are generated by the inverter in the range of some $\mathrm{kHz}$. Thus filters are necessary to reduce the interharmonics. But due to the high frequencies, in general the construction of the filters is easier. 


\section{Harnessing of Wind Energy Resource and Cost Effect}

The generator is playing the big role in any wind energy resource. Typically, the wind energy cost is defined by the initial cost of the WTG [20]. In general, the electricity produced by any WTG that is installed in a windy area can be considered less expensive than the same unit if installed in a less windy area. In average, the wind farm will pay back all the cost of the energy used in its manufacture within three to four months of operation.

The modern WTGs are designed for operation age of more than twenty years and at the end of its operation age, the area can be restored at low financial and environmental costs. In contrast to the fossil fuel power stations or the nuclear power stations, wind energy is a form of development which can be essentially reversible.

The current WTG can produce electricity $70-85 \%$ of the operation time, but it generated electricity has different outputs depending on the wind speed. Over the year, it is typically generating about $30 \%$ of the theoretical maximum output energy and this is defined as its load factor. The load factor of any conventional power station is on average $50 \%$. The modern WTG should generate enough energy to meet the demands of more than a thousand homes over the course of a year. The generating cost of electricity from wind has fallen dramatically over the past few years [21].

It is expected that by 2020 , many countries wind farms will be generating electricity at 2 -cents/kWh, making it cheaper than all other sources of electricity. As an example, in the USA the cost fallen between 1982 and 2012 is from 38 cents/kWh to about 5-cents/kWh (upper graph in Figure 5) [1]. It is also shown in Figure 5 (lower graph) that wind energy capacity almost doubled every three years and with every doubling prices fell by $15 \%$.

Moreover, wind-powered electricity is significantly cheaper than solar-powered electricity throughout most of the country. Figure 6 shows the Levelized Cost of Energy (LCOE) [2] for unsubsidized wind and solar build-outs. The cost ranges listed above each data point reflect different areas of the United States. The costs of solar-powered electricity are higher, but was fallen in five years (2009-2014), from a range of $\$ 394 / \mathrm{MWh}$ to $\$ 86 / \mathrm{MWh}$.

In addition, there is no fuel requirement or no waste related costs once the wind farm is in place and its fuel is free and widely available.

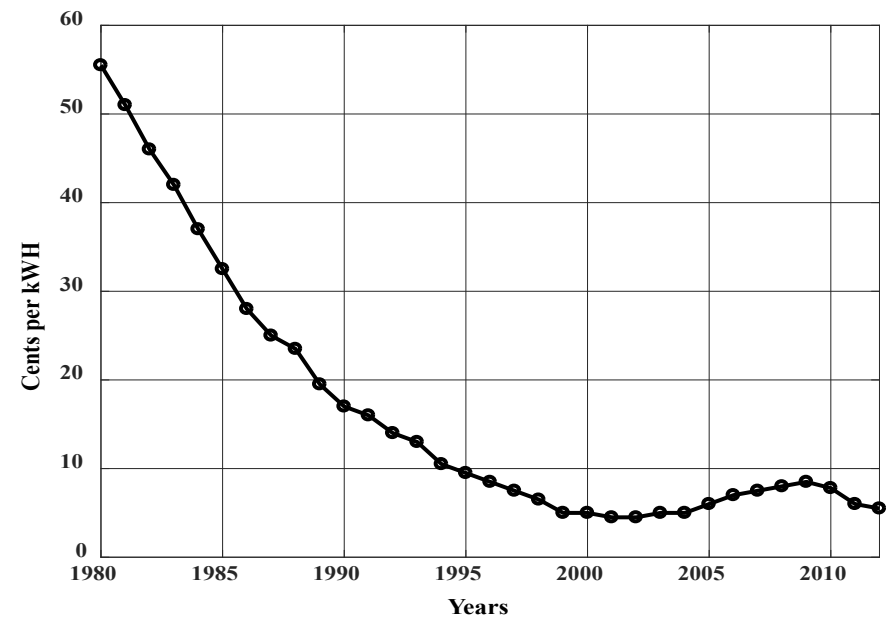

Onshore and offshore wind energy is needed in future to meet the challenging targets on climate change.

The onshore wind farm is more economical than development one offshore. However, a more offshore wind farms are now under construction. Thus, wind energy prices will go down as the industry will gain more and more experience [22].

\section{From Micro-Grid with Suitable Energy to Supply Power to an Isolated Community}

Micro-grids are modern, localized, small-scale grids, contrary to the traditional, centralized electricity grid (macro-grid). Microgrid generation source can disconnect from the centralized grid and operate autonomously, strengthen grid resilience and help mitigate grid disturbances. Also, micro-grid generation source can include stationary batteries, fuel cells, solar, wind, or other energy sources.

The multiple dispersed generation sources and ability to isolate the micro-grid from a larger network would provide highly reliable electric power. Produced heat from generation sources such as micro-turbines could be used for local process heating or space heating, allowing flexible trade-off between the needs for heat and electric power.

All kinds of conventional power stations, such as coal-fired, gas and nuclear powered plants, as well as hydroelectric dams and large-scale solar power stations are centralized for wide area and often electricity produced require to be transmitted over long distances. By contrast, Distributed Energy Resources (DER) which typically uses renewable energy sources are decentralized, modular, more flexible technologies and are located close to the load they serve. Some of isolated communities in the world do not have the electricity to provide the standard of lifestyles. The reasons why they do not have any electricity to serve their normal life can be summarized as follows:

- They are located too far from the main grid

- Planned cut-off

- Isolation from modern communities.

The developments of technology in the field of wind energy have introduced many advantages that made electricity more accessible in the world especially to those isolated communities. Distributed diesel generators have high reliability, low capital requirements and are easy

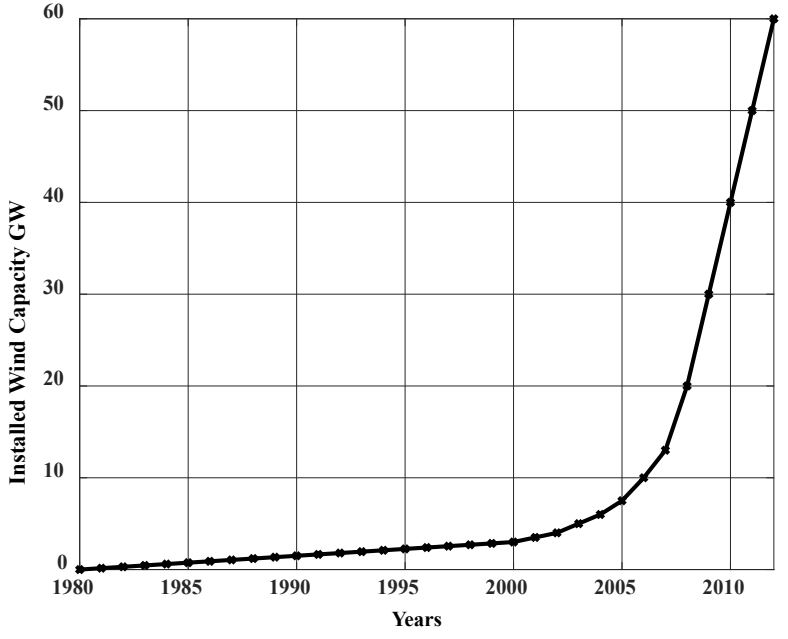

Figure 5: Deployment and cost for U.S. Land-Based wind. 

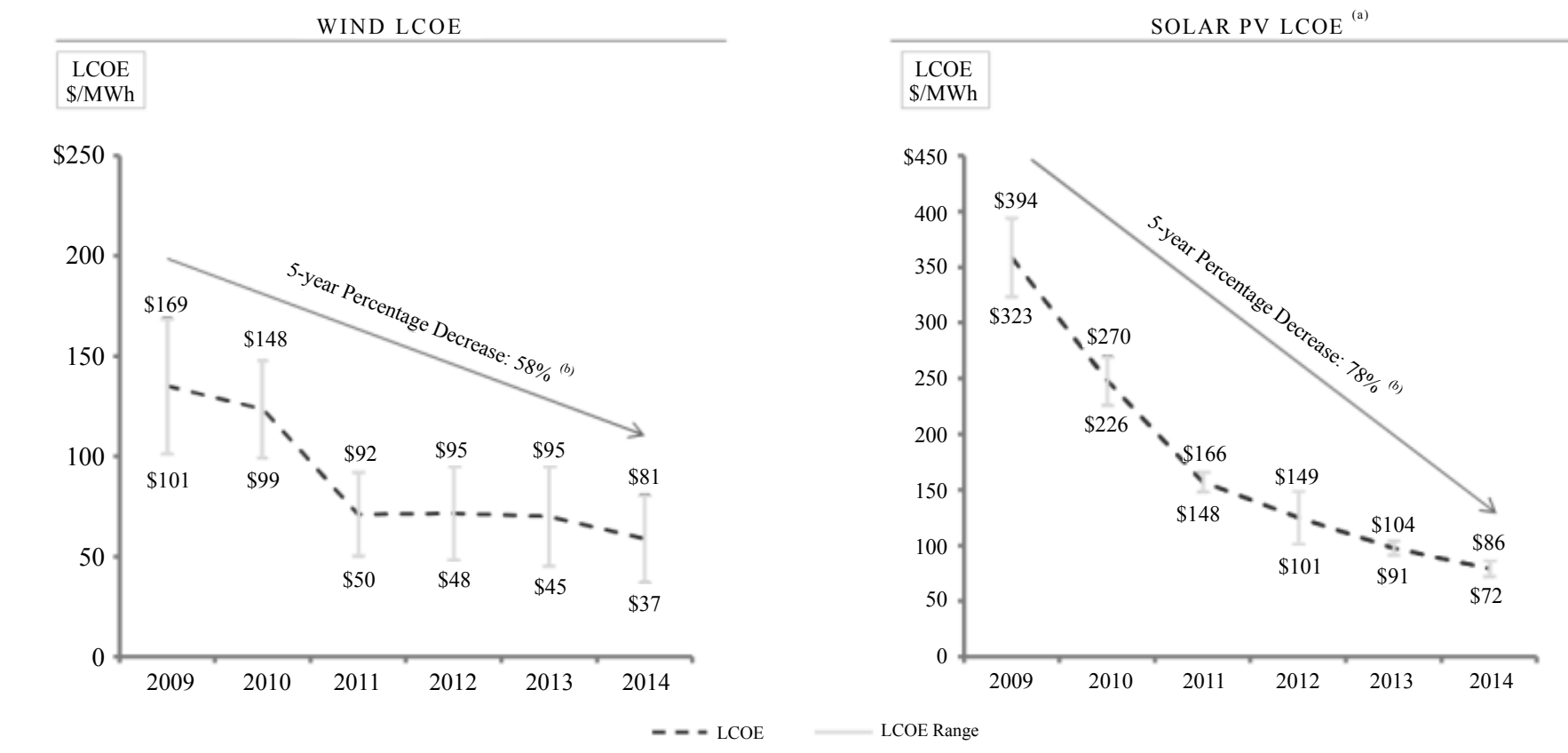

Source: Extremetech.com

Figure 6: LCOE for unsubsidized wind and solar build-outs.

to deploy, but on the other hand, they are producing more harmful emissions and their economic costs are increasing rapidly.

The expense of operating conventional power plants is growing as a result of the increasing fuel and delivery prices. This will affect the result in the running cost to reach as much as $1000 \%$ of its initial capital outlay cost in the first year of operation. Transmission lines can be another possibility to supply power to an isolated community. However, the costs associated with the assembling and the maintenance of these transmission lines can be prohibitively very high [23]. Another disadvantage is associated with reliability issues. Damages in transmission lines may cause the system black out.

As mentioned before, both wind and solar energy are have high initial outlay but comparatively low operating costs compared to others sources of energy. With the advent of the technological developments, the initial costs of wind energy sources system are being reduced. The price of wind energy systems has been decreases considerably in the last decade which make them to become competitive and thus making them a more viable option.

WTGs can be distributed energy resources or they can be built at utility scale. Distributed generation from wind hybrid power systems combines wind power with other DER systems. One such example is the integration of WTGs into solar hybrid power systems, as wind tends to complement solar because the peak operating times for each system occur at different times of the day and year.

The typical considerations on reliability of such system are:

- Viability and unit sizing,

- Energy storage techniques, control procedures,

- The systems internal connections.

The analysis of the data that is specific to various sites and in terms of the appropriate power sources, has been always useful to renewable energy sources systems [20]. It's usual that the WTG generator have a higher generation rate during the night hours, due to the stronger and more constant wind at nights. On the other hand, Photovoltaic (PV) cells can produce power during the daytime hours only. Combining the sources of WTG generators and Photovoltaic cells, however, will not satisfy the reliability requirements. In order to deliver required power to all customers, a backup power source is required [20].

The output power of renewable resources changes due to weather conditions instead of the loads and, as such, energy storage is seen to be very important to a Renewable energy sources system. Today, power systems often incorporate a variety of energy storage techniques, as part of energy storage systems (Hybrid), for loss of supply events. The energy storage has numerous different types which are available commercially.

A comparison of the several energy storage techniques available should be done order to attain the most suitable one for a specific Renewable energy sources system. The conventional energy storage techniques are limited by energy capacity. A fuel cell allowing constant power production can be chosen as the energy storage, because it can reach a maximum power production over a required duration. To provide electricity to the isolated communities by using renewable energy system, the micro-grid should have the following components:

- A maximum power captured from the PV panels.

- The WTGs need to be installed in the right place to meet the maximum power.

- The energy storage system provides effective backup power and energy to meet the demand.

- A sufficient power should be supplied from the proton exchange membrane fuel cell when the demand exceeds the available generation. 
- All the major components in the system must be commercially available.

The power quality issues are crucial in connecting renewable power sources as wind power or PV panels. Therefore, it's needed to connect the power sources through power converter and apply appropriate control scheme in order to stabilize the frequency and voltage to the one that is used for commercially $(50$ or $60 \mathrm{~Hz})$.

The choice of an appropriate WTGs or PV panels for an array installation depends on the site resource characteristic and must be taken into the account. Considerations for choosing WTG generators and the photovoltaic array include: initial cost, maintenance costs, lifetime, the availability of device and power characteristic. The cost of generation (per $\mathrm{kWh}$ ) is an important factor and usually can be determined by comparing both the resource outline and power production to the total component costs [24].

\section{WTG-PV-Fuel Cell Hybrid Generation System}

The choice of the type of WTG that can be fit to a wind profile conditions could be difficult. In fact, the electric generator selection for wind power mainly depends on several criteria: structure, converter topology, environment (location where the WTG is installed), performances, and most of all the cost. Therefore, selecting the most appropriate WTG for a wind power is can be challenging task. For the wind profile conditions outlined in the Figure 7, there are many options and one of these options is selecting two generators of 850$\mathrm{kW}$ low speed WTG during the times when PV is offline and one during the times when PV is online. The remainder of the power can be contributed by the energy storage system (i.e., fuel cells).

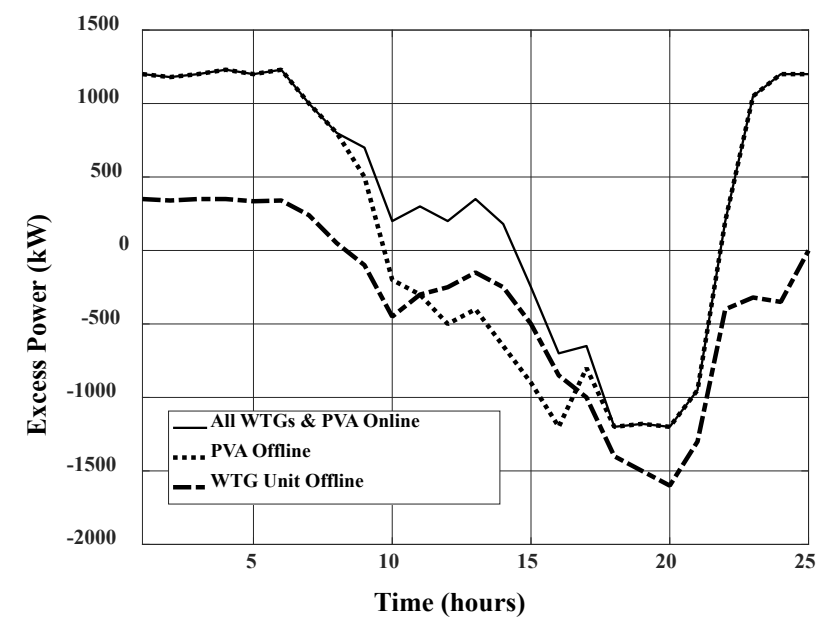

Source: Redrawn from futurepowernow.com

Figure 7: 1700kW WTG, 1000kW PV array and $1300 \mathrm{~kW}$ fuel cell.

The multiple WTGs installed should allow for the possibility of one WTG outage without significantly affecting the system. For the duration of the times in which the PV array is in operation, the wind speed can be half the nominal speed of the selected WTGs. Therefore, an array with a capacity of $400 \mathrm{~kW}$ at $600-\mathrm{W} / \mathrm{m}^{2}$ which may have a nominal capacity of 3.5-MW is not feasible or necessary.

As the capacity of the PV array must be limited, a nominal $1 \mathrm{MW}$ PV array can be considered for the system, composing nearly 4000 panels. This nominal value of $1 \mathrm{MW}$ PV array can be quite capable to fully complement the WTGs during the times when the irradiation level is at its peak. This commercial PV array system can supply $200 \mathrm{~kW}$ at $400 \mathrm{~W} / \mathrm{m}^{2}$. The energy storage system can accounts for any further power requirements.

\section{Conclusion}

With its advantages of being non-pollutant and easy to capture the power in high capacity, WTGs have become the most promising clean energy sources. The benefits of wind energy can be surmised as follow:

- It does not need fuel,

- It is more a pollution-free and

- It does not produce any toxic or radioactive waste.

In addition, Electrical Energy from wind energy sources can be a better choice from price point of view. When the WTGs are installed in arrays on a farmland, the land area that is required for the WTGs installation is only a $2 \%$ and the rest is allocated for farming, livestock, and other uses. In conclusion, the effective harness of electrical energy that comes from WTG is very high because of the pollution free, price that fall down time by time and no need fuel, therefore, wind power is one of the most growing in the renewable electrical energy.

\section{References}

1. Razavieh A, Sedaghat A, Ayodele R, Mostafaeipour A (2017) Worldwide wind energy status and the characteristics of wind energy in Iran, case study: the province of Sistan and Baluchestan. International Journal of Sustainable Energy 36: 103-123.

2. Price TJ (2005) James Blyth-Britain's first modern wind power pioneer. Wind Engineering 29: 191-200.

3. Shepherd DG (1990) Historical development of the windmill. National Aeronautics and Space Administration, Office of Management, Scientific and Technical Information Division.

4. Vestergaard J, Brandstrup L, Goddard RD (2004) A brief history of the wind turbine industries in Denmark and the United States. Academy of international business (Southeast USA Chapter) Conference Proceedings, Citeseer; pp. 322-327.

5. Lund H (2005) Large-scale integration of wind power into different energy systems. Energy 30: 2402-2412.

6. Ackermann T, Söder L (2000) Wind energy technology and current status: a review. Renew Sust Energ Rev 4: 315-374.

7. Association EWE (2012) Wind energy-the facts: a guide to the technology, economics and future of wind power. London: Routledge.

8. Blanco MI (2009) The economics of wind energy. Renew Sust Energ Rev 13 $1372-1382$.

9. Gipe P (1995) Wind energy comes of age. John Wiley \& Sons.

10. Amos WA (1999) Costs of storing and transporting hydrogen. National Renewable Energy Lab, Golden, CO (US)

11. Schaffarczyk A (2014) Types of Wind Turbines. Introduction to Wind Turbine Aerodynamics, Springer; pp: 7-20.

12. Zhang Y, Ula S (2008) Comparison and evaluation of three main types of wind turbines. Transmission and Distribution Conference and Exposition.

13. Turbines DW (1982) Aerodynamic loads and performance of the Darrieus rotor J Energy 6: 406-412

14. Islam M, Ting DS, Fartaj A (2008) Aerodynamic models for Darrieus-type straight-bladed vertical axis wind turbines. Renew Sust Energ Rev 12: 1087-1109.

15. Bhutta MMA, Hayat N, Farooq AU, Ali Z, Jamil SR, et al. (2012) Vertical axis wind turbine- $A$ review of various configurations and design techniques. Renew Sust Energ Rev 16: 1926-1939.

16. Slootweg J, Haan SWHD, Polinder H, Kling WL (2003) General mode for representing variable speed wind turbines in power system dynamics simulations. IEEE T Power Syst 18: 144-151. 
Citation: Abdolkhalig A, Fang Q, Mohamed A (2018) Effective Harness of Wind Energy Turbines. J Electr Electron Syst 7: 256. doi: 10.4172/23320796.1000256

17. Heier S (2014) Grid integration of wind energy: onshore and offshore conversion systems. John Wiley \& Sons.

18. Blaabjerg F, Chen Z, Kjaer SB (2004) Power electronics as efficient interface in dispersed power generation systems. IEEE T Power Electr 19: 1184-1194.

19. Carrasco JM, Franquelo LG, Bialasiewicz JT, Galvan E, PortilloGuisado RC, et al. (2006) Power-electronic systems for the grid integration of renewable energy sources: A survey. IEEE T Ind Electron 53: 1002-1016.

20. Ackermann T (2005) Wind power in power systems. John Wiley \& Sons.
21. Lantz E, Hand M, Wiser R (2012) Past and Future Cost of Wind Energy: Preprint. National Renewable Energy Laboratory (NREL), Golden, CO.

22. Quaschning V (2016) Understanding renewable energy systems. EPDF Routledge.

23. Gyugyi L, Schauder CD, Sen KK (1997) Static synchronous series compensator: a solid-state approach to the series compensation of transmission lines. IEEE T Power Deliver 12: 406-417.

24. Branker K, Pathak MJM, Pearce JM (2011) A review of solar photovoltaic levelized cost of electricity. Renew Sust Energ Rev 15: 4470-4482. 